\title{
Rekontruksi Pikukuh Tilu dalam Manajemen Babarit pada Upacara Serentaun Cigugur Kuningan
}

\author{
Euis Suhaenah, Ai Juju Rohaeni, Wanda Listiani \\ Insititut Seni Budaya Indonesia (ISBI) Bandung \\ Jalan Buahbatu no.212 Bandung
}

\begin{abstract}
The research found the community management theory especially the babarit management with pikukuh tilu concept and the babarit management model in traditional ceremonies. This research used the qualitative descriptive analysis. Field observation applied as the first step. The observation focuses on interview and event recording. The interview was conducted with some informants such as artists who involved in seren taun. Depth interview technique through the main informan is used to get the valid data for the solid result and comprehensive desription. The research result refers to the Sundanese mindset with the pikukuh tilu concept in traditional ceremonies through the three steps of the babarit management proses; ngajayak, babarit, nutu.
\end{abstract}

Keywords: pikukuh tilu, community mangement, tradisional ceremonies, babarit, cigugur Kuningan

\begin{abstract}
ABSTRAK
Penelitian ini menemukan teori manajemen komunitas khususnya konsep pikukuh tilu dalam manajemen babarit dan model manajemen babarit dalam upacara adat. Penelitian ini menggunakan metode deskriptif analisis kualitatif, sebagai langkah awal pengumpulan data dilakukan dengan mengadakan obervasi lapangan. Hal ini menitikberatkan pada pengamatan yang didukung dengan wawancara dan perekaman kejadian. Wawancara dilakukan dengan pelaku, tokoh yang terlibat langsung, dan tokoh seniman yang terlibat di dalamnya. Teknik wawancara yang mendalam dengan cara memilih informan kunci guna mendapatkan validitas data yang menghasilkan deskripsi yang lebih utuh dan menyeluruh. Hasil penelitian merujuk pada pola pikir masyarakat Sunda Wiwitan dengan konsep pikukuh tilu yakni ngaji badan, tuhu/mikukuh kana tanah, madep ka ratu-raja. Dalam upacara adat ada 3 (tiga) tahapan dalam proses pengelolaan manajemen babarit yakni, ngajayak, babarit, nutu.
\end{abstract}

Kata kunci: pikukuh tilu, manajemen komunitas, upacara adat, babarit, Cigugur Kuningan 


\section{PENDAHULUAN}

Upacara seren taun di Cigugur Kuningan sebagai penghayatan ajaran Agama Jawa-Sunda (AJS), dipergunakan juga sebagai sarana politik untuk mengekspresikan perlawanan yang bersifat non-fisik terhadap kolonial Belanda pada masa jaman penjajahan, yakni dengan penyelenggaraan adat istiadat dan budaya yang tertuang di dalamnya. Upacara seren taun sebagai representasi ucapan syukur sesuai dengan ajaran spritual Kyai Madrais Agama Jawa-Sunda yaitu Anjawad lan anjawab roh susun-susun Kang den Tunda, yang merupakan filosofi agama Jawa-Sunda. Filosofi AJS dimaksudkan sebagai tugas manusia untuk menyusun, menjaring, dan memilih serta membuang sifat-sifat yang terdapat pada roh hurip tanah yang disempurnakan dengan cara upacara. Manusia harus menggunakan sir-rasa pikir untuk mencari eksistensi diri dan mengimani kumpulan roh-roh tersebut. Dengan kata lain bahwa manusia sebagai "kuburan roh" dalam hal ini harus mampu menjawab anjawad lan anjawab roh-roh dalam diri agar sempurna ketika kembali kepada penciptanya. Manusia berkewajiban memenuhi sampuraning hirup sajatining mati yaitu hidup yang sempurna apabila hidup sesuai dengan kehendak Sang Pencipta. Apabila mati, mati sejati dan berpulang kepada Sang Pencipta sebagai konsep kesempurnaan hidup dalam agama Jawa-Sunda (AJS). Untuk menjawab sampuraning hirup sajatining mati dan mencari jati diri sebagai manusia dengan ciri kemanusiaannya maka harus dijalani pikukuh tilu yakni ngaji badan, tuhu/mikukuh kana tanah, madep ka ratu-raja. Pikukuh tilu merupakan pemaparan budaya spiritual dalam seren taun Cigugur Kuningan.

Babarit dalam upacara adat seren taun di Kuningan adalah rangkaian upacara syukur yang dilakukan dengan do'a oleh masing-masing pemuka agama. Do'a terse- but pada umumnya adalah ucapan syukur dan permohonan tentang kerukunan umat beragama serta doa sebagai permohonan agar Negara Kesatuan Republik Indonesia (NKRI) diberikan kedamaian dan cepat terhindar dari kondisi yang terpuruk akhir-akhir ini. Doa dari para rohaniawan tersebut ditutup dengan rajah pohaci yang dibacakan oleh Pangeran Djatikusumah yang pada intinya adalah untuk memohon kepada dewa-dewi serta kepada yang maha Kuasa tentang upacara seren taun yang dilaksanakan. Babarit memiliki makna do'a atau dzikir bersama. Dalam arti luas babarit adalah model sebuah organisasi yang bernilai dalam kehidupan masyarakat Cigugur Kuningan, masyarakat yang terbangun dalam periode yang sangat panjang berevolusi bersama masyarakat dan lingkungan dalam sistem lokal, sehingga nilai-nilai tersebut diyakini oleh masyarakat setempat sebagai kebenaran dan menjadi pedoman dalam melakukan sesuatu.

Artikel ini mengkaji permasalahan keberadaan pikukuh tilu dalam manajemen babarit di upacara seren taun Kelurahan Cigugur Kecamatan Cigugur Kabupaten Kuningan, yang merupakan salah satu konsep pikukuh tilu dalam manajemen komunitas masyarakat sawah-ladang. Selanjutnya, pembahasan difokuskan pada proses penghayatan pikukuh tilu dalam manajemen tradisi pada babarit di upacara adat seren taun masyarakat Cigugur Kuningan, dari proses perilaku hingga bentuk komunikasi selama upacara tersebut berlangsung. Seiring dengan hal ini, pembahasan diarahkan juga bagaimana konsep pikukuh tilu dalam manajemen babarit dalam kegiatan upacara seren taun. Persepsi dan interpretasi atas proses dan tindakan yang didasarkan pada perasaan dan pengalaman bersama menjadi sangat penting dikaitkan dengan pikukuh tilu dalam penyelenggaraan berbagai upacara adat seren taun. 


\section{METODE}

Penelitian ini menggunakan metode diskriptif analisis kualitatif. Sebagai langkah awal pengumpulan data dilakukan dengan mengadakan observasi lapangan. Hal ini menitikberatkan pada pengamatan yang didukung dengan wawancara dan perekaman kejadian. Data kualitatif untuk penelitian seni pertunjukan didapatkan dari sumber-sumber tertulis, sumber lisan, artefak, peninggalan sejarah serta sumbersumber rekaman (Soedarsono, 1999:192). Sebelum terjun ke lapangan terlebih dahulu dilakukan studi pustaka atau library research sebagai upaya memahami dan mengamati interaksi obyek. Hasil pengamatan yang dapat dianalisis bersama hasil wawancara dan rekaman video.

Wawancara dilakukan dengan pelaku, tokoh yang terlibat langsung, dan tokoh seniman yang terlibat di dalam upacara seren taun. Teknik wawancara yang mendalam dengan cara memilih informan kunci guna mendapatkan validitas data yang menghasilkan deskripsi yang lebih utuh dan menyeluruh. Para informan dalam penelitian ini terbagi atas tiga macam yaitu; informan pangkal, informan ahli dan informan biasa (Abu Hamid, 1989:7). Informan pangkal adalah orang yang mempunyai pengetahuan luas tentang berbagai persoalan yang ada dalam masyarakat Cigugur Kuningan misalnya budayawan. Informan ahli adalah tokoh yang terlibat langsung di dalamnya, yang memiliki pengetahuan tentang seluk-beluk upacara adat ritual seren taun sedangkan informan biasa adalah para pemusik, penari, pendukung yang tergabung dalam ruang lingkup seren taun Cigugur Kuningan.

Analisis data dilakukan dengan cara mengidentifikasi dan menemukan konsep pikukuh tilu dalam manajemen babarit dalam upacara seren taun. Langkah selanjutnya dari hasil penelitian dituangkan dalam bentuk deskriptif analisis.

\section{HASIL DAN PEMBAHASAN}

\section{Konsep Pikukuh Tilu sebagai Pemaparan Budaya Spritual dalam Seren Taun}

Pikukuh tilu merupakan tuntunan kesempurnaan hidup. Pada dasarnya, manusia hidup menuju Purwawisesa yakni sabda Tuhan yang dijiwai oleh pancaran kemanusian sejati. Manusia adalah mahluk religius, mahluk sosial dan mahluk budaya. Mahluk religius artinya bahwa manusia sadar dan yakin akan Sang Penciptanya yaitu Tuhan Hyang Maha Esa. Kita ada karena cipta karyanya, sebagai mahluk sosial, bahkan kita ini tidak hidup sendiri, kita harus hidup bersama orang lain dan harus menjalin hubungan antar sesama, antar bangsa, saling mengasihi serta saling menghargai untuk mewujudkan kesejahteraan bersama. Sebagai mahluk budaya, bahwa kita dalam hidup bermasyarakat dalam pergaulan hidup sehari-hari harus menjungjung tinggi norma etika. Hal ini selaras dengan sifat manusia sebagai mahluk yang paling mulya, mahluk yang memiliki derajat dan martabat yang lebih tinggi daripada mahluk-mahluk ciptaan Tuhan lainnya (Nana Gumilang, 2013:28).

Konsep pikukuh tilu pemaparan budaya spiritual dalam upacara seren taun adalah ngaji badan, tuhu Imikukuh kana tanah, madep ka ratu-raja.

(1) Ngaji badan. Terdiri dari dua kata yaitu ngaji dan badan. Ngaji dapat diartikan memahami atau menyadari sedangkan badan berarti segala sifat yang terdapat di sekeliling kita yang dapat diketahui atau dirasakan dengan pancaindera. Jadi ngaji badan memiliki pengertian memahami dan menyadari adanya sifat-sifat lain yang ada di sekeliling kita dan mempunyai cara-cara serta karakteristik masing-masing. Kita harus menyadari dalam kehidupan ini terdiri dari Tri Daya Eka Karsa artinya tiga taraf kehidupan yakni taraf hidup nabati (hidup tapi pasif), taraf hidup hewani (hidup aktif tapi hidup berdasarkan insting semata), taraf 
hidup insani (hidup manusia yang didasari oleh akal, rasa, dan budi). Dalam kesadaran ini kita harus menginsyafi bahwa segala sifat yang ada disekeliling dapat memberi pengaruh secara langsung maupun tidak langsung, Hal ini disebabkan bahwa Dzat atau daya ada dalam Roh hurip tanah $P a-$ kumpulan memiliki karakteristik serta ciriciri sesuai dengan fungsinya. Ngaji badan bila disadari dan selalu mengoreksi diri agar tetap berada dalam sifat-sifat pribadi sebagai manusia. Melalui ngaji badan semakin menyadari bahwa manusia hidup tidak sebatang kara melainkan hidup bersamasama dengan seluruh ciptaan Tuhan lainnya. Dalam hidup sehari-hari kita berinteraksi dengan sekeliling baik itu melalui yang ditangkap dengan pancaindra maupun apa yang dimakan dan diminum. Intropeksi sejati akan menghayati makna terdalam dari hidup, bahwa hidup, "teu daya pangawasa anging kersa nu Kagungan Cipta". Dengan demikian dapat diwujudkan menjauhkan diri dari sifat-sifat iri, benci, munafik dan perbuatan yang dapat menyakitkan atau merugikan orang lain. Dalam kehidupan manusia sebaiknya ditanmakan semangat cinta kasih, tolong-menolong, dan gotongroyong.

(2) Tuhu/mikukuh kana tanah, pengertian tuhu kana tanah, tanah diasumsikan sebagai tanah adegan dan tanah amparan. Tanah adegan ialah raga, jasmani atau salira, di tanah adegan itulah menjelma jirim, jisim dan Aku. Jirim yaitu wujud yang memiliki bentuk dan dapat dilihat serta diraba (raga/ jasmani). Jirim adalah tempat pangancikan (tempat tinggal), jisim yang memiliki ules watek (karakteristik), sedang jisim adalah pangancikan hurip. Perpaduan antara jirim dan jisim akan mewujudkan (aku). Tanah amparan adalah tanah yang dipijak. Yang dimaksud tuhu kana tanah bukan berarti yang berwujud bumi, melainkan tuhu atau mikukuh kepada kebangsaan. Jadi, yang dimaksud dengan tanah amparan adalah sifat pri- badi bangsa. Maksudnya, agar kita selaku manusia telah diciptakan menjadi anggota suatu bangsa harus dapat menghargai dan mencintai bangsanya. Arti kata, menghargai adalah bahwa kita harus memelihara memakai serta melahirkan cara-ciri bangsa sendiri. Dalam Paguyuban Adat Karuhun Urang atau ajaran penghayatan Agama Jawa-Sunda (AJS) sudah menjadi keharusan bahwa setiap bangsa harus dapat menghargai dan mencintai kebangsaannya sendiri, saling menghormati dan menghargai antar bangsa satu bangsa dengan bangsa lainnya. Karena adanya cara-ciri manusia dan cara-ciri bangsa adalah kehendak Tuhan sendiri (sudah menjadi hukum adikodrati). Jelasnya apabila akan menunjukkan eling kepada Tuhan Yang Maha Esa, maka segala ciptaan-Nya harus dihargai yang dalam pelaksanaannya harus menjungjung tinggi cara-ciri manusia dan cara-ciri bangsa.

(3) Madep ka ratu raja, arti kata madep adalah mengarah. Dikatakan madep ka ratu raja yang dimaksud disini bukan berarti ratu raja dalam sifat wujud seseorang akan tetapi mengandung makna ratu nu ngararata dan raja nu ngajagat rata. Keduanya mengacu pada makna sempurna.

- Madep ratu-raja (3), cipta, rasa, karsa atau sir, rasa, dan pikir.

Ketiga unsur ini disebut juga Tri Daya Eka Karsa, artinya tiga dalam satu, satu dalam tiga. Menurut tuntunan Agama JawaSunda (AJS) diungkapkan, "Pisahna heunteu ngajadi dua, tunggalna heunteu ngahiji".

- Mandep ratu-raja (2), hukum keseimbangan dalam hidup atau adanya sifat berpasangan seperti pria-wanita, siangmalam, baik-buruk, dan sebagainya.

- Mandep ratu-raja (4). Aktifitas kedua tangan dan kedua kaki sebagai pengejawantahan, penyeleksi akhir dari proses "wiwaha yuda nagara", Pancaran daya ditentukan oleh kemampuan (waruga).

- Mandep ratu-raja (5). Lima Pancaran Daya Sukma Salira yang dalam wujudnya 
ngaraga, rasa ciptaning pikir, getaran karakteristik dalam interaksi hidup. Melalui pancaran pancaindera yaitu mata (indera penglihatan), hidung (indera pencium), lidah (indera pengecap rasa), telinga (indera pendengar), dan kulit (indera perasa/peraba). Lima Pancaran Daya Sukma Sejati yaitu getar kesucian Illahi yang memancar dalam roh manusia yaitu awas tan mata, dangu tan kuping, ambung tan irung, ucap tan lambe dan rasa tan rampa. Lima bangsa di dunia yang terdiri dari ras Kaukasoid (kulit putih/ bangsa Eropa), ras Mongoloid (kulit kuning/ bangsa Jepang, Cina, dsbnya), ras Negroid (kulit hitam/negro, Melannesia, Polinesia), ras Americana (kulit merah/bangsa Indian) dan ras Austronesia (kulit sawo matang, rumpun bahasa Melayu). Cara-ciri manusia; welas asih, tata krama, undak usuk, budi daya, budi basa dan wiwaha yuda nagara. Cara-ciri bangsa rupa, adat, bahasa, aksara dan kebudayaan.

- Mandep ratu-raja lilima; sifat dan fungsi indera yaitu, pancaran indera rohani yaitu suatu daya yang bergetar dari dam hati nurani. Pancaran indera jasmani yaitu suatu daya yang bergetar karena adanya rangsangan dari alam sekitarnya.

- Mandep ratu-raja (6), tunggal wujud manusia seutuhnya.

Rangkuman Mandep ratu-raja adalah dalam hidup selalu diselubungi oleh macam-ragam kehendak atau keinginan. Oleh karena kita harus selalu waspada dalam pengamatan terhadap jalannya sir, rasa, dan pikir, harus selalu dipertimbangkan lebih dahulu, apakah kehendak sir, rasa dan pikir itu sesuai dengan kehendak Sang Pencipta atau tidak.

Kewaspadaan dan ketelitian terhadap adanya sifat jenis kelamin, yang masingmasing mempunyai daya tarik, sifat dan tugasnya. Kita harus sadar dan waspada jangan sampai bergerak oleh pengaruh nafsu yang tidak selaras dengan sifat-sifat bangsa.
Begitu pula sewaktu ada kehendak dan keinginan menggunakan kedua tangan dan kedua kaki, hendaknya waspada dan sadar, bahwa kita adalah mahluk manusia dimana dalam gerak dan tingkah laku serta tindakanpun harus sesuai dengan sifat-sifat dan cara-ciri sendiri sebagai manusia.

Terlebih sewaktu menggunakan panca indera. Pada indera adalah suatu alat atau jembatan penghubung antara kita dan alam sekitarnya. Melalui jalan ini pula sering datang pengaruh-pengaruh dari luar sifatsifat manusia atau dari lain kebangsaan.

Panca indera disebut juga lilima, artinya di sini walaupun dalam sifat panca indera sama, akan tetapi sifat-sifat bangsa yang satu dengan yang lain berbeda ciri-cirinya.

Yang terakhir dikatakan ratu raja artinya wujud kita masing-masing. Wujud kita adalah manusia, mahluk ciptaan Tuhan, yang diberi tugas mewujudkan kedamaian, di alam lahir sesuai dengan sifat-sifat kodrat yang diberikan kepada manusia yaitu perikemanusiaan.

Jelaslah adanya konsep pikukuh tilu pemaparan budaya spritual sebagai syarat mutlak menyembah kepada Tuhan Yang Maha Esa, kaitannya dengan upacara seren taun dalam komunitas ajaran Agama JawaSunda (AJS) atau Sunda Wiwitan.

Pikukuh tilu merupakan tuntunan kesempurnaan hidup. Pada dasarnya manusia hidup menuju Purwawisesa yakni sabda Tuhan yang dijiwai oleh pancaran kemanusian sejati. Manusia adalah mahluk religius, mahluk sosial dan mahluk budaya. Mahluk religius artinya bahwa manusia sadar dan yakin akan Sang Penciptanya yaitu Tuhan Hyang Maha Esa. Kita ada karena cipta Karyanya, sebagai mahluk sosial, bahkan kita ini tidak hidup sendiri, kita harus hidup bersama orang lain dan harus menjalin hubungan antarsesama, antarbangsa, saling mengasihi serta saling menghargai untuk mewujudkan kesejahteraan bersama. Sebagai mahluk budaya, bahwa kita dalam 
hidup bermasyarakat dalam pergaulan hidup sehari-hari harus menjungjung tinggi norma etika. Hal ini selaras dengan sifat manusia sebagai mahluk yang paling mulya, mahluk yang memiliki derajat dan martabat yang lebih tinggi daripada mahluk-mahluk ciptaan Tuhan lainnya (Nana Gumilang, 2013: 28)

\section{Manajemen Babarit dalam Upacara Adat Seren Taun di Cigugur Kuningan}

Babarit adalah sebuah sistem perhelatan dalam bentuk ritual seren taun. Pelaksanaannya telah berlangsung selama ratusan tahun dan bagi masyarakat Cigugur Kuningan, upacara tersebut memiliki nilai sakral. Meskipun zaman telah banyak berubah, penduduk pemilik ritual itu terus melestarikan adat warisan nenek moyang mereka. Upacara yang dikaitkan dengan persembahan untuk Dewi Padi, Sanghyang Sri Pohaci, pada pelaksanaanya diiringi oleh kesenian berbagai seni pertunjukan. Pola pikir masyarakat sawah dan peladang dalam konsep manajemen babarit tersirat dalam pemetaan persembahan hasil bumi yang dipersembahkan dalam seren taun dalam acara ngajayak.

Konsep manajemen seren taun terbagi atas tiga tahap yakni ngajayak babarit, nutu. Konsep tersebut mengacu pada pola pikir masyarakat Sunda lama (ladang) yang dikenal dengan sebutan tritangtu. Tritangtu, atau pola tiga, adalah sebuah sistem atomik, yakni hubungan tiga unsur yang satu sama lain tidak dapat dipisahkan. Pola tersebut merupakan salah satu artefak masyarakat ladang atau budaya huma. Dengan demikian, maka bisa diperkirakan bahwa upacara adat seren taun telah ada sejak masa berladang. Padi, sebagai makanan pokok, sumber hidup dan kehidupan, dimaknai sebagai suatu yang sangat sakral. Dalam bahasannya, Jakob Sumardjo (2003:305) menjelaskan bahwa, "padi merupakan emanasi dari benih Rama dan emanasi Nyi

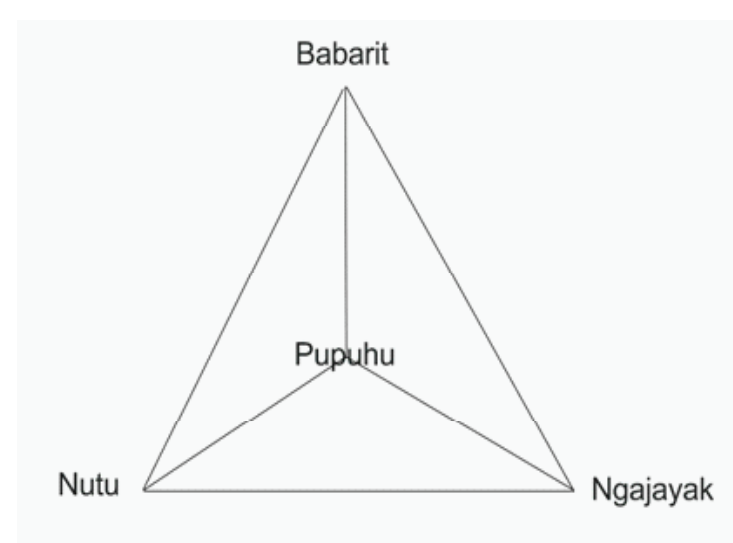

Gambar 1. Model Manajemen Babarit

Pohaci".

Upacara adat seren taun, dalam praktiknya memang terkait dengan Nyi Pwah Aci, sang Dewi Padi, yang dalam waktu tertentu selalu diupacarakan oleh masyarakat Cigugur Kuningan. Dalam hal ini senada dengan falsafah mereka terhadap Dewi Padi dan Dewi Pwah Aci atau Pohaci (dewi dari seluruh tanaman). Pemahaman masyarakat tentang Dewi Pwah Aci tidak hanya pada pengertian dewi padi tetapi lebih luas mencakup hasil seluruh pertanian yang ada di Cigugur Kuningan. Objek padi lebih dimaknai berdasarkan kebutuhan pokok dalam kehidupan sehari-hari sehingga dapat mewakili hasil bumi, ungkapan pemuliaan Dewi Pwah Aci sebagai ibu dari roh hurip tanah pakumpulan yang termaktub dalam ajaran AJS.

Inti upacara seren taun adalah Nutu (menumbuk padi). Upacara nutu merupakan salah satu upacara yang dilaksanakan dan sudah masuk dalam agenda tahunan pemerintah daerah dan masyarakat $\mathrm{Ku}$ ningan yang diperingati oleh komunitas adat dn pengikut aliran kepercayaan atau AJS (Agama Jawa-Sunda). Upacara Nutu mengangkat padi sebagai objek pokok dan hasil seluruh pertanian yang ada di Cigugur Kuningan. Upacara Nutu sebagai penghormatan terhadap Dewi Padi dan Dewi Pwah Aci atau Pohaci (dewi dari seluruh tanaman). Berdasarkan nara sumber 
lisan, Emilia Djatikusumah menjelaskan; dalam seren taun digunakan sebutan Pwah Aci sebagai Roh hurip tanah Pakumpulan (segala tanaman berasal dari tanah), dan sebutan Ibu Pertiwi (The Mather God). Padi sebagai simbol yang memiliki dimensi dan nilai mitos kesuburan yakni simbol untuk mengekspresikan hidup masyarakat yang hidupnya menyatu dengan alam seperti konsep yang terdapat dalan Agama Jawa Sunda (AJS) (Emilia Djatikusumah, wawancara 3 Maret 2016 di Paseban Kuningan).

Upacara seren taun merupakan perkembangan dari Upacara Nutu menjadi seren taun setelah Agama Jawa-Sunda (AJS) yang dideklarasikan oleh Pangeran Sadewa Alibassa Widjajaningrat yang dikenal dengan nama Kyai Madrais. Upacara seren taun ditetapkan pada tanggal 22 Rayagung (menurut kalender tradisi Sunda, 22 besar menurut sistem kalender Jawa) yang bertepatan dengan hari kelahiran putra Kyai Madrais yang bernama Pangeran Tedja Buana. Tanggal 22 Rayagung selanjutnya dimaknai sebagai merayakan Keagungan Tuhan. Oleh karena bulan Rayagung adalah bulan terakhir atau sebagai tutup tahun, maka nama upacara Nutu diungkapkan sebagai ucapan syukur yang dirayakan setiap akhir tahun disebut Upacara seren taun. Kemudian perayaan upacara ini dilanjutkan oleh putranya yang bernama Tedja Buana, yang dilanjutkan lagi oleh putranya bernama Pangeran Djatikusumah hingga sekarang. Emilia Djatikusumah menjelaskan, bahwa jumlah 22 menjadi ukuran dan simbol padi yang dibagikan dalam dalam seren taun, yakni yang ditumbuk berjumlah 20 kuintal/2 ton padi dan 2 kuintal lagi untuk bibit ditanam padi (Emilia Djatikusumah, 3 Maret 2016).

Berdasarkan nara sumber lisan, di masyarakat Cigugur Kuningan sebagai penghormatan para penggagas komunitas Kyai Madrais/penghayatan kepercayaan Agama Jawa-Sunda memberi gelar sebagai berikut:

(1). Pangeran Kusuma Adiningrat atau
Pangeran Surya Nata dikenal dengan Pangeran Sadewa Alibassa Kusumah Wijaya Ningrat, karena mendirikan pasantren untuk mengajarkan agama Islam di Cigugur dikenal dengan sebutan Kyai Madrais diberi gelar Rama Panyipta;

(2). Pangeran Teja Buana, putranya Kyai Madrais diberi gelar kehormatan Rama Pamedar;

(3). Pangeran Djatikusumah, putra Pangeran Teja Buana diberi gelar kehormatan Rama Panyusun; dan

(4). Pangeran Gugum Gumirat, putranya Pangeran Djatikusumah diberi gelar kehormatan Rama Anom Panggumbira (wawancara, Pius Juki 23 September 2016 di Kmp. Paser Kaler Cigugur Kuning).

Padi memiliki makna yang dapat diadopsi untuk menyampaikan berbagai hal sebagai sarana pemenuhan tujuan dari upacara syukur secara bersama-sama tanpa membedakan status sosial. Padi dapat digunakan juga sebagai sarana upacara yang berhubungan dengan pesan propaganda ajaran Agama Jawa-Sunda (AJS), pencarian identitas sosial dalam masyarakat, visualisasi tentang manusia yang hidupnya menyatu dengan alam, dan peristiwa budaya yang dikehendaki sesuai dengan misi dan visi dari pencetusnya (Hery Subiantoro, 2003:38). Hal ini dapat diamati pada struktur penyajian dalam upacara seren taun.

Struktur manajemen babarit seren taun dengan konsep tritangtu; ngajayak, babarit, dan

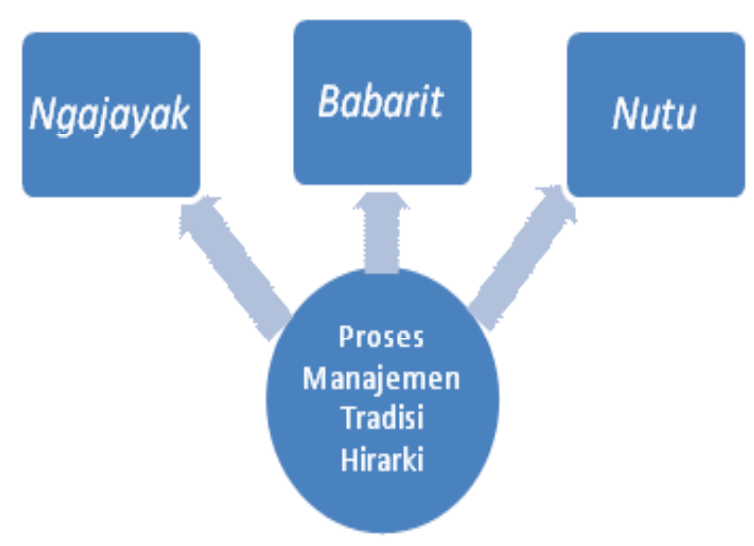

Gambar 2. Proses Manajemen Tradisi Adat Seren Taun 
nutu. Tahapan upacara adat sebagai berikut:

1. Ngajayak merupakan awalan pembuka prosesi Seren Taun, berupa penyajian pertunjukan; tari Buyung, musik Angklung Baduy, Angklung Buncis, Rengkong, Jempana. Kemduian diakhiri dengan penyerahan hasil bumi dari peserta barisan tokoh masyarakat komunitas Agama Jawa-Sunda (AJS) kepada Pangeran Djatikusumah .

2. Babarit. Istilah babarit dalam Kamus Bahasa Sunda artinya dikir bareng, maksudna nyinglar panyakit nu keur meujeuhna keur narekab, ting, singular, tingkeb (Ajip Rosidi, 2006: 78). Babarit merupakan acara membaca do'a bersama antar umat, dilakukan oleh pemuka agama, Islam, Hindu, Krestiani, dan Budha. Mereka memanjatkan do'a secara bergantian. Do'a tersebut pada umumnya adalah ucapan syukur dan permohonan tentang kerukunan umat beragama serta do'a sebagai permohonan agar negara Indonesia diberikan kedamaian dan cepat terhindar dari kondisi yang terpuruk akhir-akhir ini. Doa dari para rohaniawan tersebut ditutup dengan rajah pohaci yang dibacakan oleh Pangeran Djatikusumah yang pada intinya adalah untuk memohon kepada keselamatan karuhun serta kepada yang Maha Kuasa tentang upacara seren taun yang dilaksanakan. Istilah Rajah dalam buku Adat Istiadat Sunda artinya nama semacam jampi, untuk permohonan maaf kepada segala arwah dan keramat, serta menolak bahla (1991: 241). Babarit memiliki makna do'a atau dzikir bersama.

Nutu. Istilah nutu dalam bahasa Sunda adalah kegiatan menumbuk padi di masyarakat petani yang biasanya dilakukan oleh kaum ibu di saung lisung atau tempat khusus di belakang rumah. Nutu merupakan tahapan terakhir rangkaian seren taun, diawali dengan tumbukan pembuka tumbukan alu sebanyak 7 kali di Lesung Indung oleh Pangeran Djatikusumah, kemudian diikuti oleh pejabat, tokoh masyarakat, masyarakat yang memegang alu yang ter- libat dalam acara Nutu. Nutu merupakan kegiatan menumbuk padi untuk menjadi beras. Selanjutnya hasil tumbukan padi dibagikan kepada masyarakat yang berhak menerimanya. Sistem pembagian yang dilakukan oleh komunitas Agama JawaSunda (AJS) selaku pamangku hajat, telah diatur sedemikian rupa. Sebelumnya dilakukan pendataan siapa saja yang berhak menerima beras, selain diberikan kepada fakir miskin juga para anggota komunitas. Bagi komunitas Agama Jawa-Sunda (AJS) beras tumbukan Seren Taun memiliki kekuatan dan barokah untuk kesejahteran kehidupannya. Berdasarkan narasumber lisan Emilia Djatikusumah yang dikenal sebutan Ibu Ratu menjelaskan bahwa hasil tumbukan padi dari seren taun memiliki kekuatan yang diyakini membawa barokah, kebaikan bagi komunitas Agama Jawa-Sunda (AJS). Yakni bila disimpan di tempayan atau padaringan, kemudian beras tersebut dicampurkan untuk dikomsumsi sehari-hari. Keyakinan mereka beras yang dikomsumsi itu membawa barokah, dan tidak akan kekurangan beras sampai panen mendatang (Emilia Djatikusumah 3 Maret 2016 di Paseban Kuningan).

\section{SIMPULAN}

Konsep Pikukuh Tilu merupakan pemaparan budaya spritual sebagai syarat mutlak menyembah kepada Tuhan Yang Maha Esa, dalam kaitannya dengan upacara Seren Taun dalam komunitas ajaran Agama Sunda Jawa (AJS) atau Sunda Wiwitan.

Babarit merupakan model manajemen tradisi lama dalam upacara seren taun dengan pengelolaan yang diwariskan secara turun-temurun. Dengan kata lain, babarit adalah model organisasi tradisi yang bernilai dalam kehidupan lokal masyarakat Cigugur Kuningan, masyarakat yang terbangun dalam periode yang sangat panjang. Tradisi itu berevolusi bersama masyarakat dan lingkungan dalam sistem 
lokal dalam kehidupan masyarakat dan menjadi pengetahuan kolektif masyarakat lokal sehingga nilai-nilai tersebut diyakini oleh masyarakat setempat sebagai kebenaran dalam melakukan sesuatu.

Upacara seren taun merupakan salah satu bentuk upacara memperingati dan memberi arti baru terhadap peristiwa yang signifikan dalam hidup komunitasnya yaitu sebagai ungkapan syukur dan harapan memohon kesuburan tanah, kesuburan lahan pertanian dalam sistem mata pencaharian masyarakat Cigugur Kuningan. Meskipun ritual seren taun ini dilaksanakan dalam jangka cukup lama. Hal ini menunjukan sistem kepercayaan masyarakat Cigugur Kuningan pada hakekatnya terkait dengan sumber utama kehidupan mereka, yaitu pertanian. Upacara adat seren taun dalam praktiknya berupa kegiatan nutu yang dijadikan ritual besar, sentral dari semua ritual yang dilakukan oleh masyarakat Cigugur Kuningan.

Pengelolaan upacara seren taun merupakan manajemen tradisi lama. Dengan konsep 3 (tiga) tahapan merujuk pada pola pikir Sunda tritangtu yakni, ngajayak, babarit, nutu. Dari penelitian yang telah dilaksanakan melalui data dan fakta serta nara sumber yang ditemui, penyelenggaraan upacara seren taun telah berlangsung sampai sekarang. Konsep manajemen tradisi masyarakat lokal yang dianut oleh komunitas Kyai Madrais Agama Jawa Sunda (AJS) bisa mempertahankan salah satu kebudayaan tradisi, fungsi babarit mencerminkan gambaran dari pola kehidupan bermasyarakat yang dianut oleh komunitas Agama Jawa-Sunda (AJS) di Cigugur Kuningan. Hal ini menunjukkan masyarakat komunitas di Cigugur Kuningan dengan konsep kearifan lokal yang dianut dan dimilikinya secara turun-temurun, yakni sebagai pengelola kegiatan tradisi yang menjadi pedoman hidupnya yang dipraktikkan sehari-hari.

\section{Daftar Pustaka}

Herry Subiantoro

2003 Mitologi Ritual Padi sebagai Hirofani Dalam Upacara seren taun di Cigugur Kuningan. Jurnal Panggung No.XXVI TH 2003.

Jacob Sumardjo

2003 Simbol-Simbol Artefak Budaya Sunda. Bandung: Kelir.

Nana Gumilang

2013 Pikukuh tilu: Pemaparan Budaya Spiritual. Lembaga Pengkajian Kebudayaan Nusantara (LPKN). Bogor: PT. Rana Genta Nusantara.

Soedarsono

1999 Metodologi Penelitian Seni Pertunjukan dan Seni Rupa. Bandung: Masyarakat Seni Pertunjukan Indonesia (MSPI).

Hasil Wawancara

Emilia Djatikusumah, 3 Maret 2016 